\title{
Porosity analysis of MTA and Biodentine cements for use in endodontics by using micro-computed tomography
}

\author{
Fabricio Guerrero ${ }^{1}$, Esther Berástegui ${ }^{2}$ \\ ${ }^{1}$ DDS, MS, PhD Student, Department of Odonto-Stomatology, Faculty of Dentistry, University of Barcelona \\ ${ }^{2} \mathrm{MD}$, DDS, PhD, Professor of Endodontic, Department of Odonto-Stomatology, Faculty of Dentistry, University of Barcelona
}

Correspondence:

Department of Odonto-Stomatology

School of Dentistry

University of Barcelona

Barcelona, Spain

dr.fabricioguerrero@hotmail.com

\begin{abstract}
Guerrero F, Berástegui E. Porosity analysis of MTA and Biodentine cements for use in endodontics by using micro-computed tomography. $\mathrm{J}$ Clin Exp Dent. 2018;10(3):e237-40.

http://www.medicinaoral.com/odo/volumenes/v10i3/jcedv10i3p237.pdf
\end{abstract}

Received: 29/01/2018 Accepted: $17 / 02 / 2018$

\begin{abstract}
Background: The purpose of this study is to compare the porosity of two repair cements, White ProRoot ${ }^{\circledR}$ MTA and Biodentine ${ }^{\circledR}$. These samples were analyzed by using micro-computed microtomography.

Material and Methods: Sixteen samples were used in the study that were divided according to the composition of the materials used. White ProRoot ${ }^{\circledR}$ MTA $(n=8)$ and Biodentine ${ }^{\circledR}(n=8)$ were the samples prepared according to the manufacturer's instructions. They were placed in silicone molds of $5 \pm 0.1 \mathrm{~mm}$ in height and an internal diameter of $5 \pm 0.1 \mathrm{~mm}, 24$ hours after its preparation, the samples were scanned through a micro-CT, the porosity results were analyzed statistically by independent " $t$ " tests.

Results: It is evident that Biodentine ${ }^{\circledR}$ has better porosity properties than ProRoot ${ }^{\circledR}$ MTA. The results of the study quantify a smaller number of pores per surface, a smaller volume in each pore per $\mathrm{mm} 3$ and a lower total porosity present in samples of Biodentine ${ }^{\circledR}$ unlike ProRoot ${ }^{\circledR}$ MTA samples which is larger in both.

Conclusions: The results obtained in computerized microtomography endodontic biomaterial samples concluded that Biodentine ${ }^{\circledR}$ has a lower porosity than $\operatorname{ProRoot} \AA$ MTA.
\end{abstract}

Key words: Porosity, microleakage, micro-CT, endodontic cements.

\section{Introduction}

When performing endodontic treatment, for the sealing technique to be successful generally a sealing material and a base material are required, which are generally gutta-percha cones (1-3). Currently, there is a great diversity of endodontic materials classified according to their composition and their physicochemical properties (4-6). There are studies that have analyzed that the solubility of a duct sealing material is in permanent relationship with the porosity that this material may have $(7,8)$. The porosity and other defects of the microstructure of the endodontic sealant can produce foci of structural weakness and tensile strength of the material, producing microcracks (9).

Microcracks are defined as a decrease in the partial or total strength of a sealant, which can cause leakage within the endodontic cement in the root canal (10). Therefore, when we use the term pores when we speak of an endodontic material, we refer to the interaction between its physical properties and the type of mixture that was 
used to produce the material. Sealing or duct repair materials that are mixed manually according to the studies that have been made are more prone to subjective factors induced by the operator, thus producing more structural defects $(11,12)$.

When we talk about repairing cements, we can say that there is a wide range of endodontic materials that are classified according to their composition. The most commonly used restorative materials in endodontics in both in vitro and in vivo studies are cements based on mineral trioxide aggregate (MTA) such as ProRoot $\AA$ MTA (13) and are based on calcium silicates found in Biodentine $\mathbb{}(14,15)$.

Micro-computed tomography (micro-CT) is being used as a tool for the quantitative and qualitative analysis of endodontic materials, and due to its quality of not manipulating the sample the technique used in the current studies of porosity analysis $(4,16-19)$. In addition, the images obtained in the micro-CT allow a subsequent analysis of the material, resulting in a 3D scan of the analyzed material, which will allow observance of its internal structure and the ability to analyze the porosity of the material (18). Currently there is no study of the porosity between ProRoot ${ }^{\circledR}$ MTA (Dentsply Maillefer, Ballaigues, Switzerland) and Biodentine ${ }^{\circledR}$ (Septodont, Saint Maur des Fossés, France) that has been analyzed by micro-CT.

The objective of this in vitro study is to perform this comparison of the porosity between these two endodontic repair cements.

\section{Material and Methods}

In this in vitro study, silicone tubes were used as molds to place the repair materials $(\mathrm{n}=16)$, each silicone mold had a height of $5 \pm 0.1 \mathrm{~mm}$ and an internal diameter of 5 $\pm 0.1 \mathrm{~mm}$, filled with White ProRoot ${ }^{\circledR}$ MTA $(\mathrm{n}=8)$ and the other repair cement used was Biodentine ${ }^{\circledR}(n=8)$. All samples were prepared by a single operator following the manufacturer's instructions for powder-to-liquid ratios, preparation time and setting time.

-Sample Preparation

The silicone molds cleaned their interior light and were placed on a microscope slide. Subsequently, a repair cement was mixed, until the eight samples per group were made according to the material used, in which the endodontic cement was placed by means of an amalgam holder and a metal spatula to fill the silicone molds and in the same way with all the samples of the study. We waited 24 hours in which the materials merged completely according to the indications of the manufacturers before passing to the analysis by means of the micro-CT (SkyScan 1174, Bruker micro-CT, Kontich, Belgium). The silicone mold was not removed from repairing cements because, being a material that allows the passage of X-rays that produce the micro-CT does not influence or alter the study. In each sample that was found to be defective due to voids in the repair material in the silicone mold, the sample showing the defect was removed and replaced with a new sample.

-Scanning of micro-CT

The samples were scanned using a micro-CT (SkyScan 1174, Bruker micro-CT, Kontich, Belgium). The following scan parameters were applied: $50 \mathrm{kV}$ and 800 $\mu \mathrm{A}$ voltage source, $9.6 \mu \mathrm{m}$ pixel size, $0.80^{\circ}$ rotation to achieve $180^{\circ}$ total rotation and exposure time of 16000 ms. Using NRecon software (Skyscan), the 345 images obtained from the scan were reconstructed to show two-dimensional slices of the internal structure of the ProRoot ${ }^{\circledR}$ MTA and Biodentine ${ }^{\circledR}$ samples. Three-dimensional reconstruction, volumetric analysis and measurement of the pore volume were analyzed using CTan and CTVol (SkyScan) software of 450 cross sections of each sample.

-Statistical Analysis

The porosity values present in the endodontic repair cement samples analyzed in the study were compared using the student's " $t$ " tests for independent samples (SPSS 24.0, SPSS Inc., Chicago, IL). A value of $p<0.05$ was considered statistically significant.

\section{Results}

Through the sagittal and transverse sections of the samples (Fig. 1), it was possible to quantify the volume of each pore per $\mathrm{mm} 3$, the number of pores per surface and the total porosity present in the endodontic materials, both based on MTA and based on calcium silicate (Table 1). It has been found that the repair material based on calcium silicate Biodentine ${ }^{\circledR}$, has better properties in regard to porosity unlike the material based on mineral trioxide aggregate ProRoot $\AA$ MTA, since the results of Biodentine ${ }^{\circledR}$ in what refers to the amount of pores per surface is notably lower than those presented by MTA $(P$ $=0.000)$. In addition, the volume of each pore per $\mathrm{mm} 3$ in Biodentine ${ }^{\circledR}$ is smaller in volume than the MTA $(P=$ 0.003 ) and the total porosity is also smaller in Biodentine ${ }^{\circledR}(P=0.006)$.

\section{Discussion}

Various techniques have been used for the assessment of porosity in endodontic materials, including dye staining (20), protein loss (21), bacteria leakage (22), mercury porometry (23), capillary flow porometry (24) and scanning electron microscopy (25). Computed microtomography is a three-dimensional imaging technique that leaves the sample intact and is being used as an alternative means to determine the porosity of a biomaterial (19). The use of computed microtomography in endodontics has been one of the specialties in which the micro-CT is being used, since the endodontic materials can be evaluated as well as the techniques of duct filling $(26,27)$. 


\section{Biodentine ${ }^{\circledR}$}
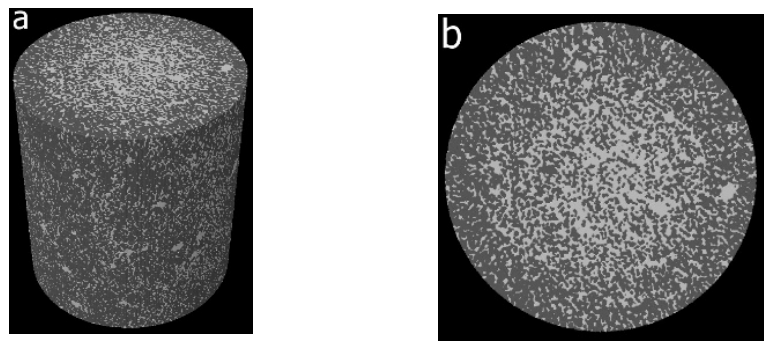

\section{ProRoot $\circledast$ MTA}
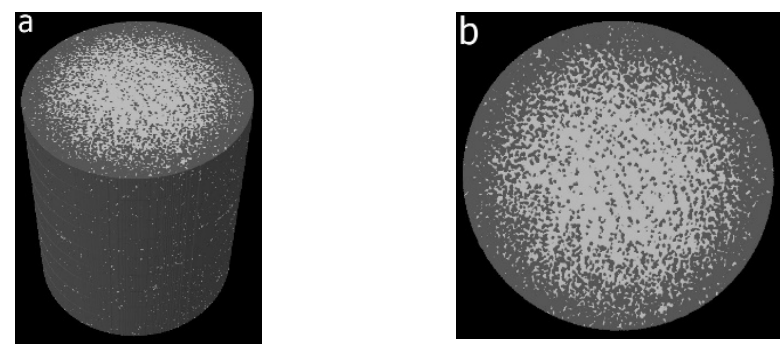

Fig. 1: Porosity images of Biodentine ${ }^{\circledR}$ and ProRoot ${ }^{\circledR}$ MTA obtained through micro-CT. (a) 3D model with Presence of endodontic material and porosity. (b) Cross section of the repair material and present porosity of Biodentine ${ }^{\circledR}$ and ProRoot ${ }^{\circledR}$ MTA. The white color represents the presence of pores and the gray is the repair material without porosity. sage of bacteria is not only of coronal origin but also of apical origin. Mutal \& Gani [8] corroborated it in a later study, in which they concluded that if a sealant has a high porosity it shows a high microfiltration, thus allowing the periradicular tissue fluids to penetrate the root canal system.

In an in vitro study carried out by Basturk et al. (19), they analyzed various properties of the MTA-based endodontic materials, including porosity, comparing two ProRoot ${ }^{\circledR}$ MTA and MTA Angelus ${ }^{\circledR}$ materials. These samples were analyzed by means of a micro-CT and the results concluded that there is no difference between these two repair cements as regards the porosity of the material. In the same way De Souza et al. (16) conducted an in vitro study in which they compared the porosity of four restorative endodontic materials, Ceramicrete ${ }^{\circledR}$, iRoot BP Plus ${ }^{\circledR}$, ProRoot ${ }^{\circledR}$ MTA and Biodentine ${ }^{\circledR}$. These materials were analyzed and evaluated by a micro-CT to calculate the porosity, and the results affirmed that there is no difference in porosity between these materials. However, Mokeem et al. (4) stated that the resin-based materials produce less porosity inside the material, since they conducted a study comparing RealSeal ${ }^{\circledR}$, EndoRez ${ }^{\circledR}$, GuttaFlow and TubliSeal ${ }^{\circledR}$, through a micro-CT. The results and conclusions of the

Table 1: Number of pores per area, volume of each porosity per mm3 and total porosity of Biodentine ${ }^{\circledR}$ and ProRoot ${ }^{\circledR}$.

\begin{tabular}{|l|c|c|c|}
\hline & Biodentine $^{\circledR}$ & ProRoot $^{\circledR}$ MTA & P-value \\
\hline Number of pores per area & $736,5 \pm 258,01$ & $10780 \pm 1334,26$ & 0,000 \\
\hline Volume of each pore per $\mathrm{mm}^{3}$ & $2 \pm 0,05$ & $2,08 \pm 0,43$ & 0,006 \\
\hline Total porosity\% & $4,71 \pm 0,14$ & $4,95 \pm 0,12$ & 0,003 \\
\hline
\end{tabular}

Behr et al. (28) reported that the powder-liquid relationship, temperature and porosity can change the mechanical properties of endodontic cements. Therefore, the variables related to the mixing and placement of the material are key factors that influence the performance of endodontic cements. It reaffirms Ørstavik et al. (29) since it refers that the physical properties of root canal sealant and repair materials vary according to the composition and handling of each material.

Mutal (30) analyzed the repercussions of coronary patency on endodontically treated teeth in their study, in which they stated that even if a good obturation treatment is performed, its durability depends on several factors, including coronal filling and the use of a cement sealer that does not produce porosity, because the pas- aforementioned studies differ from those obtained in the present study since at the time of comparing ProRoot ${ }^{\circledR}$ MTA with Biodenitne ${ }^{\circledR}$ to evaluate the repair material that produces less porosity, the results showed that both materials have porosity, but that Biodentine ${ }^{\circledR}$ is the repair cement that has the least microfiltration inside the material and the results have a statistically significant difference.

\section{Conclusions}

Within the limitations presented by the in vitro study, the results of the analysis of the images obtained through the micro-CT in the samples of the repairing cements with regard to porosity, it is observed that the repair cement Biodentine ${ }^{\circledR}$ presents less porosity compared to the porosity present in ProRoot ${ }^{\circledR}$ MTA. 


\section{References}

1. Goldberg F, Massone EJ, Artaza LP. Comparison of the sealing capacity of three endodontic filling techniques. J Endod. 1995;21:1-3.

2. Gok T, Capar ID, Akcay I, Keles A. Evaluation of different techniques for filling simulated $\mathrm{C}$-shaped canals of 3-dimensional printed resin teeth. J Endod. 2017;43:1559-64.

3. Kim JA, Hwang YC, Rosa V, Yu MK, Lee KW, Min KS. Root canal filling quality of a premixed calcium silicate endodontic sealer applied using gutta-percha cone-mediated ultrasonic activation. J Endod. 2018;44:133-138.

4. Mokeem A, Hammad M, Silikas N, Qualtrough A, Watts D. A laboratory evaluation of the physical and mechanical properties of selected root canal sealers. Int Endod J. 2010;43:882-8.

5. Zhou H, Shen Y, Zheng W, Li L, Zheng Y, Haapasalo M. Physical properties of 5 root canal sealers. J Endod. 2013;39:1281-6.

6. Torres F, Bosso M, Espir C, Cirelli JA, Guerreiro JM, Tanomaru M. Evaluation of physicochemical properties of root-end filling materials using conventional and Micro-CT tests. J Appl Oral Sci. 2017;25:374 80.

7. Da Mata M, Santos P, Cilense A. Influences of the insertion method in glass ionomer cement porosity. Microsc Res Tech. 2012;75:667-70. 8. Mutal L, Gani O. Presence of pores and vacuoles in set endodontic sealers. Int Endod J. 2005;38:690-6.

9. De-Deus G, Scelza MZ, Neelakantan P, Sharma S, Neves A, Silva EJ, et al. Three-dimensional quantitative porosity characterization of syringe- versus hand-mixed set epoxy resin root canal sealer. Braz Dent J. 2015;26:607-11.

10. Almeida J, Gomes B, Ferraz C, Souza F, Zaia A. Filling of artificial lateral canals and microleakage and flow of five endodontic sealers. Int Endod J. 2007;40:692-9.

11. Sisli S, Ozbas H. Comparative micro-computed tomographic evaluation of the sealing quality of ProRoot MTA and MTA Angelus apical plugs placed with various techniques. J Endod. 2017;43:147-51.

12. Duque J, Fernandes SL, Bubola J, Duarte M, Camilleri J, Marciano $M$. The effect of mixing method on tricalcium silicate-based cement. Int Endod J. 2018;51:69-78.

13. Hashem AA, Hassanien EE. ProRoot MTA, MTA-Angelus and IRM used to repair large furcation perforations: sealability study. J Endod. 2008;34:59-61.

14. Nowicka A, Wilk G, Lipski M, Kołecki J, Buczkowska J. Tomographic evaluation of reparative dentin formation after direct pulp capping with $\mathrm{Ca}(\mathrm{OH}) 2$, MTA, Biodentine, and dentin bonding system in human teeth. J Endod. 2015;41:1234-40.

15. Silva LA, Pieroni KA, Nelson FP, Silva RA, Hernandéz GP, Lucisano MP, et al. Furcation perforation: periradicular tissue response to Biodentine as a repair material by Histopathologic and indirect immunofluorescence analyses. J Endod. 2017;43:1137-42.

16. De Souza E, Nunes M, Roter J, De Assis J, De Almeida A, DeDeus G. Tridimensional quantitative porosity characterization of three set calcium silicate-based repair cements for endodontic use. Microsc Res Tech. 2013;76:1093-8.

17. Gandolfi M, Parrilli A, Fini M, Prati C, Dummer P. 3D micro-CT analysis of the interface voids associated with Thermafil root fillings used with $\mathrm{AH}$ Plus or a flowable MTA sealer. Int Endod J. 2013;46:253-63.

18. Zakizadeh P, Marshall SJ, Hoover CI, Peters OA, Noblett WC, Gansky SA, et al. A novel approach in assessment of coronal leakage of intraorifice barriers: a saliva leakage and micro-computed tomographic evaluation. J Endod. 2008;34:871-5.

19. Basturk F, Nekoofar M, Gunday M, Dummer P. Effect of various mixing and placement techniques on the flexural strength and porosity of mineral trioxide aggregate. J Endod. 2014;40:441-5.

20. Torabinejad M, Higa RK, McKendry DJ, Pitt TR. Dye leakage of four root end filling materials: effects of blood contamination. J Endod. 1994;20:159-63.

21. Saghiri MA, Lotfi M, Saghiri AM, Vosoughhosseini S, Fatemi A, Shiezadeh V, et al. Effect of $\mathrm{pH}$ on sealing ability of white mineral trioxide aggregate as a root-end filling material. J Endod. 2008;34:1226-9.
22. Nair U, Ghattas S, Saber M, Natera M, Walker C, Pileggi R. A comparative evaluation of the sealing ability of 2 root-end filling materials: an in vitro leakage study using Enterococcus faecalis. Oral Surg Oral Med Oral Pathol Oral Radiol Endod. 2011;112:e74-7.

23. Formosa LM, Damidot D, Camilleri J. Mercury intrusion porosimetry and assessment of cement-dentin Interface of anti-washout-type Mineral Trioxide Aggregate. J Endod. 2014;40:958-63.

24. Hong ST, Bae KS, Baek SH, Kum KY, Lee WC. Microleakage of accelerated mineral trioxide aggregate and Portland cement in an in vitro apexification model. J Endod. 2008;34:56-8.

25. Saghiri MA, Shabani A, Asatourian A, Sheibani N. Storage medium affects the surface porosity of dental cements. J Clin Diagnostic Res. 2017;11:ZC116-ZC119.

26. Swain M, Xue J. State of the art of micro-CT applications in dental research. Int J Oral Sci. 2009;1:177-88.

27. Ahmed HM. Nano-computed tomography: current and future perspectives. Restor Dent Endod. 2016;41:236-8.

28. Behr M, Rosentritt M, Loher H, Kolbeck C, Trempler C, Stemplinger $\mathrm{B}$, et al. Changes of cement properties caused by mixing errors: the therapeutic range of different cement types. Dent Mater. 2008;24:1187-93.

29. Ørstavik D, Nordahl I, Tibballs JE. Dimensional change following setting of root canal sealer materials. Dent Mater. 2001;17:512-9.

30. Mutal L. Permeabilidad coronaria en piezas dentarias tratadas endodónticamente. PhD Thesis, Universidad Nacional de Córdoba, Córdoba, Argentina, 1998.

\section{Conflict of Interest}

The authors deny any conflicts of interest related to this study. 